\title{
> A insurreição em Levantando do chão : da ordem social às vicissitudes do romance
}

\author{
> Insurrection in Levantado do chão : \\ from social order to vicissitudes of the novel
}

\section{por Thaís Cristina da Silva}

Mestra em Literatura pelo Programa de Pós-Graduação em Literatura e Práticas Sociais da Universidade de Brasília (UnB). E-mail: thais.unb2014@gmail.com. ORCID: 00000002-7539-4433.

\section{Resumo}

O artigo realiza uma análise sobre o gênero narrativo por meio da leitura do romance Levantado do chão, de José Saramago. Para isso, discutimos as vicissitudes do romance e da epopeia amparados nas perspectivas teóricas de Bakhtin e Lukács sobre o romance e, posteriormente, analisamos elementos constitutivos da presente obra. A pesquisa constata a subversão das formas narrativas mediante um projeto de reescrita da história portuguesa por Saramago, marcado por um ideário de retomada e valorização do povo português oprimido, à margem dos processos histórico-sociais da nação.

Palavras-chave: Romance. Epopeia. Tempo Histórico. Povo Português. Saramago.

\begin{abstract}
The article analyzes the narrative genre by reading the novel Levantado do chão, by José Saramago. For this, we discussed the vicissitudes of the novel and the epic supported by theoretical perspectives of Bakhtin and Lukács on the novel and, later, we analyzed the constituent elements of this work. The research finds the subversion of narrative forms through a project for the rewriting of Portuguese history by Saramago, marked by an idea of recovery and appreciation of oppressed Portuguese people, on the margins of historical-social processes of the nation.
\end{abstract}

Keywords: Novel. Epic. Historical Event. Portuguese People. Saramago. 


\section{Considerações iniciais}

No seu canônico estudo Epos e Romance: sobre a metodologia do estudo do romance, Bakhtin ressalta o caráter inacabado do romance. ${ }^{1}$ Tal gênero dialoga com seu tempo histórico, o que de certo modo ocasiona na composição do romance um efeito perdurante do presente, este inacabado, o qual o gênero estaria eternamente em processo de constituição. Trata-se de uma forma mutável, a constituir sua ossatura mediante contato com a história. Não obstante a este fato, outro ponto essencial a se destacar é a parodização a outros gêneros. A forma romanesca, na concepção bakhtiana, estaria ligada a um esforço de assimilação, integração e travestimento de gêneros, reinterpretando-os e dandolhes outro tom. Essa incorporação, que acontece de forma não passível, acabou conferindo ao romance um tom de autocrítica e consciência poética, indispensável para o seu fortalecimento como gênero no século XVIII.

Por tais características, o romance, segundo o autor, ancora em uma perspectiva de "renovar os próprios fundamentos da literaturidade e da poeticidade dominantes"2. Esta defesa que o romance toma para si entra em confronto com o epos, que seria o correlato do romance. Bakhtin, no seu ensaio, não almeja traçar uma teoria sobre o romance, e o próprio atenta sobre isso, mas é nas dissonâncias entre tais gêneros que se expõem as vicissitudes do romance. Não cabe aqui elencar todas as características que contrastam estes gêneros, mas é importante salientar que o pensamento de Bakhtin converge na impossibilidade de coexistência da epopeia e do romance.

\footnotetext{
${ }^{1}$ Mikhail Bakhtin, Epos e Romance: sobre a metodologia do estudo do romance, 1990, p. 397.

2 Ibidem, p. 403.
} 
A ascensão do romance é proveniente da desintegração da épica, isso porque o mundo onde habita a epopeia é impenetrável no mundo do romance. As marcas mais distintas do romance apresentam-se como a contraparte da forma épica: no épico, o mundo é reflexo de uma condição fechada e absoluta, o chamado passado épico absoluto, e sua forma chega até nós de modo acabado e perfeito. Tudo é absoluto e nada é inacabado. Esta perfeição confere um ar de distância, uma representação longínqua ao mundo prosaico do romance inoperante a mudanças.

A ausência de relatividade que compõe o mundo épico parece atingir a perspectiva bakhtiana. Em se tratando de Bakhtin, parece-nos haver, em sua teoria, uma distância insuperável na relação epos/romance, mais de contrastes evidentes do que de uma propensa continuidade, um elo de transição natural. Esta oposição, que soa inflexível, atinge o princípio da pluralidade do romance. Sendo estes dois gêneros correlatos, é inevitável uma assimilação da forma épica, até mesmo para assim poder debatê-la.

Paralelo a tal perspectiva, György Lukács confere um equilíbrio à relação entre epopeia e romance. Assim como Bakhtin, Lukács disserta em sua Teoria do Romance a contraposição do mundo clássico e moderno, o qual aquele se assimila ao da perspectiva bakhtiana: há uma totalidade do homem para com o cosmos. ${ }^{3}$ A epopeia seria a expressão desse coletivismo, dessa nação personificada na figura do herói clássico, contrapondo-se ao romance, que seria a disjunção do indivíduo com a coletividade e, consequentemente, a perda dela. Ambos os autores são unânimes ao afirmar a impossibilidade de realização da epopeia no

\footnotetext{
${ }^{3}$ György Lukács, A teoria do romance, 2000, p. 29.
} 
mundo moderno, mas Lukács estende os pormenores dessa relação a uma esfera não plenamente polarizada. O crítico, ao teorizar sobre o gênero, baseia seu estudo na perspectiva de Hegel, que define o romance como a epopeia da vida burguesa. Tal expressão interage com dois gêneros que até então pareciam se anular.

Nas palavras do teórico Lukács:

Quando Hegel chama o romance de epopeia burguesa, põe uma questão que é, ao mesmo tempo, estética e histórica: ele considera o romance como o gênero literário que, na época burguesa, corresponde à epopeia. $O$ romance, por um lado, tem as características estéticas gerais da grande narrativa épica; e por outro, sofre as modificações trazidas pela época burguesa, o que assegura sua originalidade. ${ }^{4}$

O romance surge como um produto de dissolução da forma épica. Ele aspira todos os traços característicos dessa forma, mas jamais a atinge plenamente, pois as bases em que se fixa o romance - a sociedade burguesa impossibilita a totalidade de mundo que paira na épica. De certa forma, para Lukács, "a contradição da forma do romance reside precisamente no fato de que este gênero literário, como epopeia da vida burguesa, é a epopeia de uma sociedade que destrói a possibilidade da criação épica" ${ }^{5}$.É na impossibilidade que se constrói o gênero romance. As relações de gênero em Lukács ganham conexões mais profundas e difusas, pois não há rupturas, mas continuidades. Assim, os grandes romances só se tornam grandes romances por trazer um

\footnotetext{
${ }^{4}$ Idem, O romance como epopeia burguesa, 2011, p. 195.

${ }^{5}$ Ibidem, p. 202.
} 
elemento épico à vida burguesa, o que nos permite muitas vezes fazermos associações de gêneros problemáticas.

A figuração da realidade cotidiana é a base da matéria romanesca. Não é mais o mundo nobre e de grandes feitos que ganha espaço, porque o romance dialoga com seu tempo histórico; sendo assim, o que se sobressai é a figuração da vida privada do burguês, como também a alienação do homem oprimido pelo sistema. O que se tem é a luta individual do sujeito que não se reconhece na coletividade a qual faz parte, uma vez que as conexões homem-mundo se perdem em face de um sistema que o exclui. A tradição coletiva é substituída pela experiência individual e o termo realismo ganha espaço no romance pela figuração dessa vida cotidiana ordinária.

Lukács subverte as expectativas ao dar um novo significado a este termo, que acaba por dinamizar ainda mais as relações da épica com o romance. Não nos desdobremos em todas as implicações que o termo realismo possa abarcar, pois são muitas e cabe um estudo pormenorizado, mas é importante ressaltar que o realismo na estética lukacsiana está na capacidade de o autor representar todas as contradições e dinâmicas histórico-sociais no romance, pois, na interpretação de Lukács, realismo da vida cotidiana "não passa de um meio para a configuração concreta e viva dos grandes conflitos sociais da época" ${ }^{6}$.

A mera cópia do cotidiano travestida de realismo não acrescenta traço épico ao romance. Coube ao Lukács da fase marxista indicar onde este se encontra. Já foi dito anteriormente que o mundo moderno, onde se assenta o romance, é característico de uma falta de totalidade que contrasta com o mundo

\footnotetext{
${ }^{6}$ Ibidem, p. 208.
} 
antigo. O romancista luta contra essa desintegração, busca a totalidade mesmo que saiba dessa impossibilidade. O caráter progressista frente a um capitalismo alienador dá margem ao reflexo épico no romance: na perspectiva do crítico, é preciso que a arte vá "além da realidade cotidiana média e o escritor atinja o pathos da vida privada (Balzac) ou o materialismo da sociedade burguesa $(\operatorname{Marx})^{\prime \prime}$.

O esforço épico do romance dá-se na tarefa dos romancistas em despertar a luta de classes de maneira dinâmica, viva, através das ações e situações criadas para guiar suas personagens ao caminho da tomada de consciência de seu tempo histórico e de seu papel como sujeito ativo do mundo. Despertar a atividade num mundo passivo, a totalidade em uma fragmentação, sem ignorar a contradição rica da sociedade em que se encontra; eis a epopeia burguesa. Não obstante, podemos considerar, dados os limites circunstanciais, que o romance tende a ser metamórfico à medida que se desenvolve a narrativa. $\mathrm{O}$ autor parte da matéria romanesca para alcançar o efeito epopeico, pois é ele a sua aspiração.

Lukács abre ainda espaço de discussão ao romance histórico, continuação direta do romance social do século XVIII. Revitalizando a leitura dos romances de Walter Scott, antes vista em uma chave romântica, o crítico diverge das concepções vigentes sobre o assunto ao condenar a exotização e glamourização como vitrines do passado que toca o romance histórico, sem nenhum vínculo com aspectos políticos, sociais e afins do tempo presente. A história constitui-se como processo ininterrupto de mudanças, o tempo presente se mostra histórico, pois é o construto dialético de presente e passado-entrelaçados. O sujeito somente

\footnotetext{
${ }^{7}$ Ibidem, p. 209.
} 
se constrói como tal nessa linha de mudanças no seu percurso histórico e tamanha importância amplia a história como condição de ação, não mero intermédio decorativo.

Nada muito diferente que se distinga do romance realista lukacsiano, o próprio romance histórico é um processo integrante do romance e, em nenhum momento, o crítico normatiza a categoria, mas alguns pontos merecem nota para conjeturas. A base histórica que serviu para a produção de Walter Scott foram os momentos de convulsão ideológica e econômica do continente europeu, a Revolução Francesa foi um momento-chave para profundas mudanças na reconfiguração social e política mundial. Lukács atenta que, em consequência da Revolução Francesa, o povo, pela primeira vez, viu-se como agente da história. Esta, antes restrita aos confins de salões de baile, se torna vivência e propriedade dos camponeses e camadas baixas da burguesia.

É por esse sentimento de pertencimento que se cria um despertar da história nacional; a pátria deixa de ser exclusiva e passar a ser um bem comum. Como observa Lukács, à medida que “a consciência progressiva do caráter histórico também começa a se evidenciar as condições econômicas e de luta de classes" $^{\prime \prime}$. Esse aspecto revolucionário parece-nos indispensável à constituição do romance histórico, pois complementa uma característica distinta desse gênero: a coletividade. Os momentos de crise e revolução perpassam uma união, e as correntes sociais e de cunho nacional ganham força ao considerar um sentido social-coletivo, e não individual. O romance histórico parece compreender essa força e sua importância para o surgimento de uma nova história nacional.

\footnotetext{
${ }^{8}$ Idem, O romance histórico, 2011, p. 41.
} 
Diferentemente do romance realista do século XVIII, cujo indivíduo estava irrecuperavelmente desagregado da sociedade, o romance histórico parece amparar-se num indissociável sentido de comunidade nas personagens, para que a ideia de nação possa ser trabalhada na matéria poética. Por essa razão aproxima-se do traço épico das epopeias a forma específica da temática histórica, pelo caráter espontâneo e social das ações, semelhante às atividades dos homens do mundo antigo.

As teorias de gênero expostas dialogam no consenso da ação do romance no tempo histórico - a modernidade, marcada pela queda do mundo feudal e ascensão do capitalismo - e estabelecem um diálogo, de oposição, continuidade ou ambos com o épico. Contudo, definir com precisão as vicissitudes e objetivos que tingem o romance se tornam inacabados e isentos de totalidade, sempre à disposição ao que o presente reserva. Assim, perante as especificidades que caracterizam o épico e o romance, investigamos a obra Levantado do chão, do autor português José Saramago, a fim de elucidarmos os limites, nem sempre visíveis, e as transgressões que tangem o romance.

\section{Levantado do chão: a forma narrativa como subversão da ordem social}

O dia 25 de abril de 1974 marca um período de transição na história de Portugal: irrompeu a Revolução dos Cravos, movimento que derrubou o regime do ditador António de Oliveira Salazar, de modo a estabelecer a ordem democrática e promover transformações sociais em todo o país. Portugal, que vivia desde 1926 um período ditatorial, após um golpe militar, atingiu o ápice de repressão no período do regime salazarista, proclamado em 1932, inspirado no regime 
fascista italiano. Liberdades individuais, de organização e repressão foram suprimidas pela Constituição de 1933. No fatídico dia, integrantes do Movimento das Forças Armadas (MFA) tomaram as ruas de Lisboa, exigindo o fim dessa liderança ditatorial que persistia mesmo com a morte de Salazar, sob o comando de Marcelo Caetano. O povo, visto o movimento, juntou-se a eles na rebelião e, por fim, simbolizou a luta ao colocar no cano de suas armas um cravo como agradecimento. Passada a Revolução, o que se seguiu foi uma série de disputas pelo poder. Embora livres do autoritarismo, Portugal se deparava como uma realidade de duras condições políticas e sociais, dissonantes dos ideais de Abril.

Tesche constata que, longe do período de efervescência da Rebelião, abriu-se o tempo para a reflexão do que foi revolucionado, de conjeturas e análises críticas, nos âmbitos histórico, sociológico e artísticos, o que culminou em obras significativas sobre a Revolução dos Cravos e antecedentes que compõem a história portuguesa. ${ }^{9}$ Segundo a autora, no campo das atividades literárias, ajudou muito a ausência do crivo da censura, "onde os discursos metafóricos e simbólicos perderam seu caráter de estratégia obrigatória àqueles que pretendessem criticar abertamente o regime, tornando-se escolhas"10.

No meio de uma vasta produção sobre essa era conturbada de Portugal, encontra-se José Saramago e seu romance Levantado do chão, publicado em 1980. Saramago nos apresenta à saga da família dos Mau-Tempo, camponeses pobres à margem da sociedade, que perambulam por Portugal desde o século XV, passando por importantes episódios da história do país, como a Instauração da República, a Primeira Guerra Mundial, a Guerra Civil Espanhola, a ascensão do

\footnotetext{
${ }^{9}$ Camile Tesche, História e poder: uma leitura de Levantado do Chão, 2007, p. 12.

${ }^{10}$ Ibidem, p. 13.
} 
Estado Novo e, posteriormente, sua queda. A narrativa se firma a partir da mudança, depois de tantas andanças, da primeira geração do romance: Domingos Mau-Tempo, Sara da Conceição e seu filho recém-nascido, João MauTempo, mudam para o latifúndio Alentejo. Assim, veremos, durante o intervalo de setenta anos, o nascimento, a morte, os laços familiares, amores, tomada de consciência e mudanças de atitudes dessa família, tudo isso mediado pelas suas duras condições de vida no latifúndio de Alentejo.

A partir da saga dos Mau-Tempo, Saramago constrói todo um painel histórico de mudanças da terra lusitana. Trata-se desses casos em que a ficção e a história estão indissociavelmente entrelaçadas para a construção do romance. Como apontado pela historiografia, Levantado do chão se ergue sob as bases do neorrealismo português, mas o texto se amplia na medida em que Saramago subverte toda uma estrutura textual para compor a reprodução de uma realidade cuja história se mostra conflituosa e diversificada, por meio de um relato que se alimenta das mais variadas tradições. Na percepção de Matter, a subversão da estrutura textual impulsiona o objetivo de alterar a ordem social. ${ }^{11}$

Diz o narrador, logo no início da narrativa, “Mas tudo isso pode ser contado de outra maneira"12, tal subversão faz-nos refletir sobre a identidade do romance, que transmuta entre diversas possibilidades de gênero à proporção que se redimensionam as possibilidades históricas, mesmo que seja na ficção. ${ }^{13}$ Levantado do chão realiza um trajeto de cerca de quatro séculos e carrega em seu título a semântica de um percurso que nos leva ao dia de seu levantamento. Nessa

\footnotetext{
${ }^{11}$ Michele Matter, Um épico de agora ascende em novo pilar: Levantado do chão ou uma outra epopeia burguesa, 2011, p. 32.

${ }^{12}$ José Saramago, Levantado do chão, 2013, p. 12.

${ }^{13}$ Ibidem, p. 12.
} 
trajetória de permutação, narrador, personagem, espaço e tempo modificam-se com o intuito de assumir uma linguagem que promova a história a ser lida e reconhecida.

Lélia Parreira Duarte atenta ao caráter dialógico do romance:

O romance de José Saramago é, pois, obra de contestação: apresenta-se como cruzamento de superfícies textuais, diálogo de vários escritos: do autor, do narrador, do destinatário, das personagens, do contexto atual e anterior. A história e a sociedade são vistas pelo escritor como textos que ele lê e em que se inscreve ao reescrevê-los; tornam-se assim ambivalentes, pois adquirem um significado novo, embora conservem também o antigo. ${ }^{14}$

O texto direciona sua composição para que seja possível um diálogo com a história, no qual essa deve ser de acesso a todos a todo tempo. O romance parte do princípio de buscar ou refazer uma memória coletiva. Ao contar a saga dos Mau-Tempo, Saramago realiza uma metonímia de toda a história do povo português oprimido, cuja voz não está nos registros históricos. É essa parte que foi calada que o escritor português busca retratar em sua totalidade, fazendo-o através da subversão da linguagem, da assimilação de elementos da oralidade e, principalmente, do entrelaçamento de gêneros narrativos esse reconhecimento.

A narrativa de Levantado do chão abre-se em uma gênesis sobre o mundo, em que "a paisagem é sem dúvida anterior ao homem"15. O tempo provoca alterações nessa paisagem; passam-se as estações, correm os rios, morrem os animais, eventos esses que contribuíram para o surgimento da terra, que é

\footnotetext{
${ }^{14}$ Lélia Duarte, Levantado do chão, de José Saramago: a grande novidade dos anos 80, 2011, p. 11.

${ }^{15}$ José Saramago, Op. Cit., 2013, p. 11.
} 
preenchida, modificada e descoberta no eterno andar dos homens. O dinheiro compra e vende o homem e, por consequência, a terra, anterior a eles, passa a ser, para a figura do narrador, "dividida do maior para o grande, ou mais desgosto ajuntada do grande para o maior, por compra dizemos ou aliança, ou roubo esperto, ou crime estreme, herança dos avós e meu bom pais, em glória estejam"16. Nasce, assim, o latifúndio.

O romance de Saramago apoia-se na tríade Homem-Natureza-Terra, uma vez que se formaram os latifúndios, tanto as relações entre o homem e a natureza como as relações entre os homens em si tornaram-se obsoletas e inconclusas. A exploração de terras expande-se na exploração e submissão do próprio homem, em que se danifica um princípio de sua sociabilidade. Como consequência, este se volta à natureza como igual, já que as relações sociais foram desobstruídas e alienadas.

Domingos Mau-Tempo, da primeira geração dos Mau-Tempo retratada no romance, é um caso clássico dessa situação. Seu personagem é construído de modo que é inconcebível qualquer diálogo. Sua relação para com seus pares, em especial, sua mulher, Sara da Conceição, e seus filhos, é parca e brutal, uma vez que a comunicação não se efetiva; assim, Domingos encontra nas andanças um meio de se encontrar.

Se a opressão do latifúndio apagou a voz dos oprimidos na história, surge o narrador a saber sobre: “E esta outra gente quem é, solta e miúda, que veio com a terra, embora não registada a escritura, almas mortas, ou ainda vivas?" ${ }^{17}$. Uma

\footnotetext{
${ }^{16}$ Ibidem, p. 12.

${ }^{17}$ Ibidem, p. 12.
} 
nova história se conta para complementar a totalidade registral do que se perdeu, da história e da terra.

Quando favorecemos o verbo contar a narrar é porque o narrador de Levantado do chão traz uma similaridade das formas de narrar aos contadores de histórias populares. A introdução da narrativa remete a um canto épico. Matter assinala esse tom épico da narrativa e o intuito do narrador de realizar "um novo cantar épico que acolha os esquecidos da história, concedendo-lhes a fama épica e a imortalidade pelo registro da memória de suas vidas"18.

O narrador de Levantado do chão em muito se espelha à figura do contador de histórias, o qual Walter Benjamin evoca no seu estudo 0 narrador: considerações sobre a obra de Nicolai Leskov. À medida que o romance do século XVIII ganhou espaço, a própria expressão do narrar foi-se tornando obsoleta pela falta de vivacidade das experiências e segregação dos romancistas do mundo moderno.

Para Walter Benjamin, o contador de histórias

Sempre traz consigo, de forma aberta ou latente, uma utilidade. Essa utilidade pode consistir por vezes num ensinamento moral, ou numa sugestão prática, ou também num provérbio ou norma de vida - de qualquer maneira o narrador é um homem que sabe dar conselhos ao ouvinte. Mas se dar conselhos soa hoje como algo antiquado isto se deve ao fato de as experiências estarem perdendo a sua comunicabilidade. ${ }^{19}$

Benjamin afirma que a sabedoria é provedora do lado épico da verdade. A verdade do narrador vem no seu caráter onisciente e onipresente, que

\footnotetext{
${ }^{18}$ Michele Matter, Op. Cit., 2011, p. 34.

${ }^{19}$ Walter Benjamin, O narrador: considerações sobre a obra de Nicolai Leskov, 2012, p. 216.
} 
acompanha, comenta e crítica a ação, observa de fora, conhece o passado, vivencia o presente e profecia o futuro e, assim, acumula um vasto conhecimento, tanto da vida arcaica, quanto de narrativas: "Bem avisada fui, mal avisada andei, frase final que de seu cabedal literário a vizinha acrescentou, conciliando o clássico e o moderno com louvável desplante"20.

A relação narrador/personagem é marcada por diferentes tipos de interação. Observa-se que, em um primeiro momento da narrativa, o discurso é monológico e marcado pela submissão de poder, cujas vozes dos patrões do latifúndio tendem a interferir mais do que as dos camponeses, que não passam de pequenos ruídos, murmúrios e lamentos. Segundo Duarte, “o escritor descreve e narra dentro de seus pressupostos, com um discurso que é determinado pelo poder, como se viu ao endossar ele a necessidade-de os trabalhadores conviverem com a sujeira" ${ }^{21}$. Decorrida parte da narrativa, e o passar de gerações, surgem os pequenos questionamentos, as dúvidas, marcadas pela técnica de um discurso indireto livre; narrador e personagem refletem e opinam sobre as circunstâncias de opressão, até o ponto em que o próprio camponês levanta a voz na narrativa.

E tu queres dizer alguma coisa, pergunta inesperada, interpelação que sobressaltou o novel, Não sei, não tenho nada para dizer, e depois ficou calado, mas todos estavam calados, a olhar, e assim não podia ser, cinco homens sentados debaixo dum chaparro a jogar sisudo, e como não tinha mais nada a dizer, disse, -Cansamo-nos a trabalhar de noite e de dia, quando há trabalho, e não aliviamos o nosso castigo na vida faminta, cavo uns bocaditos de terra quando nos dão para cultivar, e até altas horas, e agora é um geral desemprego, o que eu queria era saber porque são estas coisas assim e se vai ser assim até morrermos todos, não há justiça se uns

${ }^{20}$ José Saramago, Op. Cit., 2013, p. 42.

${ }^{21}$ Lélia Duarte, Op. Cit., 2011, p. 4. 
têm tudo e os outros nada, e eu só queria dizer que os camaradas podem contar comigo, é só isto e nada mais. ${ }^{22}$

A onisciência do narrador não o isenta de adquirir novos conhecimentos no contato com as personagens. Seu discurso guia-os à emancipação social e à tomada de consciência, e é nesse percurso, nessa tomada de voz das personagens, que o narrador reflete sobre o próprio processo de escrita: “Distinga-se o que é reflexão do narrador e o que é pensamento de João Mau-Tempo, mas vote-se que tudo seja uma mesma certeza, e se houver erros, partilhados sejam"23. É nessa medida em que o narrador de Levantado do chão se enriquece: a trajetória de consciência das personagens é seguida da pluralidade de vozes do romance. A narrativa se emancipa no caminho de coletivização com que o narrador guia a história.

Em oposição à onisciência do narrador, estão as personagens com a divisão bem clara entre opressores e oprimidos. Essa cisão é vinculada ao espaço (ou a falta deste), conferido a cada um na história. À revelia dos latifundiários, os quais percorrem a narrativa de forma unilateral, que, em uma ironia de Saramago, até seus nomes são semelhantes - Lamberto, Floriberto, Adalberto -, são os oprimidos que operam um caminho de mudanças na narrativa. A primeira geração retratada no romance, com foco em Domingos Mau-Tempo e sua esposa Sara da Conceição, são alheios a si e a tudo o que os ronda: "Então porque entre o latifúndio monárquico e o latifúndio republicado não se viam diferenças e as parecenças eram, todas, porque os salários, pelo pouco que podiam comprar, só

\footnotetext{
${ }^{22}$ José Saramago, Op. Cit., 2013, p. 230.

${ }^{23}$ Ibidem, p. 264.
} 
serviam para acordar a fome" ${ }^{24}$. Tais personagens atravessam a narrativa alheios aos processos históricos; pior: estes são excluídos da história, e em sintoma mais grave, estão destituídos de sentido da própria esfera privativa de suas vidas, alienados do próprio núcleo familiar.

$\mathrm{Na}$ abertura do romance, que marca a ida da família a Alentejo, a decomposição dos móveis oriunda das constantes andanças da família é uma metáfora para essa decomposição das relações sociais. Esse corte de comunicação direciona o indivíduo a uma identificação maior com a natureza, uma vez que a sociabilidade é perdida; no romance, representado pelo caminhar sem rumo de Domingos que culmina em seu suicídio. A natureza aparece como o trabalho, e a realidade desse homem é sua confirmação como ente-espécie.

A mística de um regresso da natureza humana a uma vida natural e primitiva é condenada pelo filósofo Karl Marx, tido por ele como um naturalismo de aparências. Isso porque o estágio em que o homem se encontra é o resultado de um processo histórico, cujo sistema de produção em que está inserido se caracteriza como o estágio final de evolução. No prefácio de Uma contribuição para a Crítica da Economia Política, Marx atesta que o indivíduo só produz em sociedade, porque este é um ser eminentemente social e histórico, movido pelas novas forças produtivas desenvolvidas a partir do século XVI. ${ }^{25}$ Para o teórico, o indivíduo aparece dentro de um contexto mais vasto, cuja vivência em sociedade é essencial para sua constituição como sujeito e como fator de desenvolvimento de suas potencialidades.

\footnotetext{
${ }^{24}$ Ibidem, p. 35.

${ }^{25}$ Karl Marx, Prefácio, 2008, p. 45.
} 
O caminho de uma fusão indissociável que alinhe a essência do indivíduo a uma natureza primitiva, evidenciadas em um primeiro momento do romance, não surge como um campo de possibilidade, um ideal naturalista, mas sim como um grave sintoma de regressão da condição humana. As relações sociais tornamse obstruídas em face de uma ordem social e econômica que não acolhe esses sujeitos. O desenvolvimento das capacidades humanas desses personagens está sendo impedido por uma sociedade que os rejeita; a marginalização desses indivíduos é tamanha ao ponto de se realizar uma reserva ética do homem perante a natureza; ética esta que, na sociedade, não lhe é conferida, uma vez que são oprimidos pela ordem social.

O levantar do chão dá-se, pois, na efetivação dessas relações sociais, primeiro com seus núcleos familiares e, depois, para com a comunidade, mediante o reconquistar da palavra. O diálogo entre o primeiro núcleo familiar do romance é escasso e monossilábico; a partir de João Mau-Tempo e Faustina, representantes da segunda geração, há um maior envolvimento de João com a esposa e com os filhos, interação que se concretiza definitivamente na terceira geração, com Gracinda Mau-Tempo e Manuel Espada. Vale ressaltar a importância da conquista da leitura e escrita na emancipação daquela família. João Mau-Tempo é o primeiro a adquirir esse conhecimento, o que promove nele, desde cedo, dúvidas e contestações.

A tomada de consciência das personagens é adquirida mediante essa coletivização. O romance direciona-se a reestabelecer uma totalidade dessas relações, a (re)construir um sentido de nação que lhes foi retirada. À medida que as personagens interagem entre si, realizando associações com o objetivo de lutar por melhores condições de trabalho e pelo fim da exploração dos latifundiários, 
elas passam por agentes de transformação da realidade histórica, configurandoa. O agir humano interpõe-se como elemento de modificação interna e externa; os personagens crescem à proporção que uma memória coletiva é construída e partilhada.

Não apenas as personagens rumam a uma unidade, mas também o espaço em questão é construído mediante as complexas relações entre o homem e a terra; no romance, o espaço é redefinido pelas ações humanas no decorrer do tempo. O latifúndio do Alentejo configura-se como um microcosmo da sociedade portuguesa "e não falta por aí latifúndio que tenha o seu cárcere privado e o seu código penal próprio. Nessa terra faz-se justiça todos os dias, onde é que íamos parar se a autoridade faltasse" ${ }^{26}$. É nele que o reflexo de Portugal, do regime salazarista, encontra-se marcado por repressões e distinções de classe.

Vale ressaltar que a jornada é um aspecto constante no relato. Une os homens da família Mau-Tempo essa qualidade de andarilho. Domingos anda na busca por um significado, João se fixa, mas "sonha acordado, já se vê longe de Monte Lavre a caminho de Lisboa [...]"27, Antonio Mau-Tempo segue os passos do avô, com a diferença é que a própria jornada é o significado. Assim, Saramago retoma uma característica do povo português: a de desbravadores. Se, séculos atrás, eram os mares que os antepassados lusitanos exploraram, cabe agora ao povo português explorar, conhecer e contar os feitos terrenos, nas palavras do narrador, esse mar interior. Para isso, é necessário reaver essas terras, reconquistar o que antes era de todos; a efetividade dessa luta decorre da união dos oprimidos.

\footnotetext{
${ }^{26}$ José Saramago, Levantado do chão, 2013, p. 88.

${ }^{27}$ Ibidem, p. 68.
} 
O Alentejo de Saramago, no início da narrativa, é espessa e distante, e mimetiza as grandes extensões dos donos de latifúndio. O decorrer do relato converge num encurtamento de distâncias progressivamente ao aumento das interações das personagens, nas reuniões ocultas de manifestantes, nas ligações afetivas que surgem no contato e no diálogo dos habitantes de diferentes regiões - tal qual Manuel Espada e Gracinda Mau-Tempo - que cruzam seus caminhos com o mesmo propósito. O espaço público se ocupa mediante a força de consciência de coletivização: somos trabalhadores. No fim, já não é mais Monte Lavre, Éfora ou Montemor, é Portugal.

\begin{abstract}
De todos os lugares de trabalho confluem as máquinas, o grande avanço dos blindados, ai esta linguagem guerreira, quem pudesse esquecer são tratores que avançam, vão devagar, é preciso ligar com que os que vêm dos outros sítios, estes já chegaram, grita-se de um lado para o outro, e a coluna engrossou, torna-se ainda mais forte lá adiante, vão carregando os atrelados, já há quem caminhe a pé, são os mais novos, para eles é uma festa, e então chegam à herdade das Mantas, andam aqui cento e cinquenta homens a tirar cortiça, juntam-se todos com todos, e em cada herdade que ocuparem ficará um grupo de responsáveis, a coluna já leva mais de quinhentos homens e mulheres, seiscentos, não tarda que sejam mil, é uma romaria, uma peregrinação que refaz as vias do martírio, os passos desta cruz. ${ }^{28}$
\end{abstract}

Neste dia levantado e principal que encerra o romance, no meio da festa do povo e junto de Maria Adelaide, filha de Manuel e Gracinda, estão Domingos, Sara, João, Faustina, já mortos, e outros que morreram na luta pela liberdade e pela reforma agrária. Essa cena é simbólica pela fusão concomitante de passado, presente e futuro em um só tempo para ver a conquista do povo português. Em dado momento do romance, é dito que a história se repete, o que corrobora para

${ }^{28}$ Ibidem, p. 395. 
a atemporalidade do discurso de Levantado do chão, representados nos mesmos olhos azuis que se fazem presentes em Adelaide, herdados de seu avô João MauTempo que, por sua vez, herdou-os do estrangeiro que forçou a donzela séculos atrás. O que Saramago conduz em sua narrativa é que esse reprisar da história não é necessariamente o perdurar do discurso; este pode ser reinterpretado sob outro prisma: buscar, se não a totalidade do mundo, pelo menos, a totalidade do relato.

O romance se aproxima do épico à medida que o caminho da narrativa almeja uma totalidade das relações sociais. Toda a narrativa de Levantado do chão é construída nessa busca por uma totalidade fictícia: do tempo, do espaço e das relações sociais, como se o romance ansiasse pelo mundo avivado no prólogo, quando tudo era paisagem. Mas o mundo da epopeia não é mais possível no mundo moderno, pois carece do sentido absoluto. O caráter mais épico evidencia-se na promoção da ação coletiva, no agir humano a reestabelecer um mundo em que as ligações entre o homem e o mundo/ pátria se mostrem orgânicas, identificáveis. A luta épica ou a saga epopeica da narrativa de Saramago é o levantar desse chão, é dotar de consciência o homem frente à história e reaver de significado o que pertence intrinsicamente a ele, tal como o caráter diretamente social e espontaneamente público da vida, e sua relação com a terra e com a comunidade.

\section{Conclusão}

Levantado do chão, na própria concepção do título, expõe as vicissitudes de gênero presentes na narrativa de Saramago: começa com um poderoso registro de opressão dos trabalhadores camponeses e a sua realidade cotidiana e progride 
ao levantar de uma luta épica de emancipação do homem. Aproxima-se, assim, o romance à epopeia ao desbravar o mar interior de Portugal.

Também se figura na condição de romance histórico, cuja matéria ficcional não se fixa apenas no relato dos grandes acontecimentos históricos, mas no "despertar ficcional dos homens, trata-se de figurar de modo vivo as motivações sociais e humanas a partir das quais os homens pensaram, sentiram, e agiram de maneira precisa, retratando como isso ocorreu na realidade histórica"29. Tampouco, delimitam-se as tradições do romance histórico, em especial, nas transgressões do narrador e nas funções dos personagens. Não se tem aqui um herói mediano aos moldes do romance histórico scottiano; o herói só toma essa posição no romance à medida que se coletiviza. Não se trata da saga de heroicidade dos Mau-Tempo, de um destino individual que se concentra o coletivo, mas do povo português em um uno indissociável.

Acima de tudo, Levantado do chão se firma como um romance - dentre as inúmeras possibilidades do gênero - desde seu constante diálogo com a tradição do cânone português, que passa por Os Lusíadas de Camões ao romance histórico de Alexandre Herculano, à pluralidade com a assimilação de marcas populares, ao valor inacabado do romance que permite sua reescrita e, num sentido mais pleno, revela as contradições e as dinâmicas sociais de Portugal. Saramago, que se revela como seu narrador, um sábio conselheiro, guia o povo português oprimido ao caminho da tomada de consciência dos processos históricos, e a partir disso, à criação de uma memória coletiva, a se pensar os caminhos para

\footnotetext{
${ }^{29}$ György Lukács, O romance histórico, 2011, p. 60.
} 
emancipação e reescrita dessa história pós-salazarismo, seja na ficção, seja na realidade cotidiana.

\section{Referências}

BAKHTIN, Mikhail. Epos e romance: sobre a metodologia do estudo do romance. In: Bakhtin, Mikhail. Questões de literatura e de estética. São Paulo: Edunesp/Hucitec, 1990.

BENJAMIN, Walter. O narrador. Considerações sobre a obra de Nicolai Leskov. In: BENJAMIN, Walter. Magia e técnica, arte e política. São Paulo: Brasiliense, 2012.

DUARTE, Lélia Parreira. Levantado do chão, de José Saramago: a grande novidade dos anos 80. IPOTESI - Revista do Instituto de Letras da UFJF, Juiz de Fora, v. 15, n. 1, p. 201-208, jan. / jun. 2011.

LUKÁCS, György. A teoria do romance. São Paulo: Editora 34, 2000.

LUKÁCS, György. O romance como epopeia burguesa. In: LUKÁCS, György. Arte e sociedade: escritos estéticos 1932-1967. Rio de Janeiro: Editora UFRJ, 2011. LUKÁCS, György. O romance histórico. São Paulo: Boitempo, 2011. MARX, Karl. Prefácio. In: MARX, Karl. Contribuição à crítica a economia política . São Paulo: Expressão Popular, 2008.

MATTER, Michele Dull Sampaio Beraldo. Um épico agora ascende em novo pilar: Levantado do chão ou uma outra epopeia burguesa. Augustus - Revista do Centro Universitário Augusto Motta - UNISUAM, Rio de Janeiro, v. 1, p. 32-42, 2011. 
SARAMAGO, José. Levantado do chão. São Paulo: Companhia das Letras, 2013.

TESCHE, Camile Carolina Pereira da Silva. História e poder: uma leitura de

Levantado do chão. 2007. 134 f. Dissertação (Mestrado em Letras) - Faculdade de

Filosofia, Letras e Ciências Humanas. Universidade de São Paulo, São Paulo, SP.

\section{Referência para citação deste artigo}

DA SILVA, Thaís Cristina. A insurreição em Levantando do chão: da ordem social às vicissitudes do romance. Revista PHILIA | Filosofia, Literatura \& Arte, Porto Alegre, volume 2, número 1, p. 510 - 532, junho de 2020. 